\title{
MORPHOMETRIC STUDY OF PHARYNGEAL ORIFICE OF AUDITORY TUBE
}

\author{
Sandeep Mohite ${ }^{1}$, Raghunath Shahaji More2, Hemalata Mohite ${ }^{3}$
}

${ }^{1}$ Associate Professor, Department of Anatomy, Krishna Institute of Medical Sciences Deemed University, Karad, Maharashtra. ${ }^{2}$ Assistant Professor, Department of Anatomy, Institute of Medical Sciences, Banaras Hindu University, Varanasi, Uttar Pradesh. ${ }^{3}$ Tutor, Department of Anatomy, Krishna Institute of Medical Sciences Deemed University, Karad, Maharashtra.

\begin{abstract}
Eustachian tube extends from the anterior wall of the middle ear to the lateral wall of the nasopharynx at the level of inferior nasal choncha. It maintains the equilibrium of air. It is an important landmark for endoscopic evaluation in patients with chronic otitis and also for the transnasal approach to the infratemporal fossa.
\end{abstract}

\section{MATERIALS AND METHODS}

Study was carried out, 50 sagittal sections (25 right side and 25 left side) of head and neck specimens from adult formalin fixed cadavers from the Department of Anatomy, Krishna Institute of Medical Sciences Deemed University, Karad, Maharashtra, India. The pharyngeal opening of Eustachian tube was observed for its shape, size and important measurements taken with the help of sliding vernier calliper. The mean and standard deviation of these parameters were calculated.

\section{RESULTS}

The vertical length and A-P length was taken and shape was observed. Oval shape more common on right side (52\%) and triangular on left (48\%). The A-P length on right side was $8.7 \mathrm{~mm}$ on right and $7.6 \mathrm{~mm}$ on left side, which was statistically significant. The height was more on right side than on left side.

\section{CONCLUSION}

In the present work, the exact position of auditory tube can be located by various measurements. So the study will be helpful for radiologist for differential diagnosis and ENT surgeons for endoscopic evaluation in patients with chronic otitis media.

\section{KEYWORDS}

Eustachian Tube, Inferior Nasal Concha, Inferior Turbinate.

HOW TO CITE THIS ARTICLE: Mohite S, More RS, Mohite H. Morphometric study of pharyngeal orifice of auditory tube. J. Evolution Med. Dent. Sci. 2016;5(73):5385-5387, DOI: 10.14260/jemds/2016/1222

\section{INTRODUCTION}

The Auditory Tube (AT) extends from the anterior wall of the inferior nasal concha middle ear to the lateral wall of the nasopharynx, approximately at the level of the inferior nasal concha. It is derived from the first pharyngeal pouch, which during embryogenesis forms the tubotympanic recess. The distal part of the tubotympanic recess gives rise to the tympanic cavity, while the proximal tubular structure becomes the auditory tube. ${ }^{1}$ It is divided into an osseous intra-temporal portion and cartilaginous portion, which open in the nasopharynx. ${ }^{2}$ In adults the tube makes two curves before pharyngeal opening; it makes a curve which is directed downwards and forwards. The effect of infection or inflammation in middle ear, nose or nasopharynx reflects Eustachian tube, so a knowledge of anatomy and physiology of it is necessary for proper diagnosis and treatment of the diseases. ${ }^{3}$

Financial or Other, Competing Interest: None.

Submission 16-06-2016, Peer Review 10-07-2016,

Acceptance 16-07-2016, Published 12-09-2016.

Corresponding Author:

Dr. Raghunath Shahaji More,

Assistant Professor,

Department of Anatomy,

Institute of Medical Sciences,

Banaras Hindu University,

Varanasi-221005.

E-mail: psychiatry.more@gmail.com

DOI: $10.14260 /$ jemds $/ 2016 / 1222$

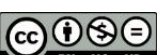

\section{MATERIALS AND METHODS}

Present study was conducted with 50 mid-line sections (25 right, 25 left side) of head and neck specimens from adult formalin fixed cadavers from the Department of Anatomy, Krishna Institute of Medical Sciences Deemed University, Karad, Maharashtra, India. The pharyngeal opening of Eustachian tube was observed for its shape and size and following measurements were taken using sliding vernier calliper of $30 \mathrm{~cm}$ length, $0.01 \mathrm{~cm}$ accuracy as shown in Fig.1,2,3.

1. Antero-posterior length (width)

2. Vertical height

3. Distance from posterior end of inferior turbinate

4. Distance from clivus-perpendicular distance

5. Distance from roof of nasopharynx

6. Distance from anterior tubercle of arch of atlas

The data was collected and tabulated and analysed statistically.

\begin{tabular}{|c|c|c|c|}
\hline \multirow{3}{*}{$\begin{array}{c}\text { Position of } \\
\text { opening }\end{array}$} & Position/Shape & Right & Left \\
\cline { 2 - 4 } & Below & 56 & 84 \\
\cline { 2 - 4 } & Behind & 36 & 16 \\
\hline \multirow{3}{*}{$\begin{array}{c}\text { Shape of } \\
\text { opening }\end{array}$} & Above & 8 & 0 \\
\cline { 2 - 4 } & Oval & 52 & 32 \\
\cline { 2 - 4 } & Triangular & 36 & 48 \\
\cline { 2 - 4 } & Round & 12 & 0 \\
\hline
\end{tabular}

Table 1: Showing Different Positions and Shape of Pharyngeal Opening of Auditory Tube (All In \%) 


\begin{tabular}{|c|c|c|c|c|c|c|c|c|c|c|c|c|}
\hline \multirow[t]{2}{*}{ Parameters } & \multicolumn{2}{|c|}{$\begin{array}{l}\text { Width } \\
\text { (cm) }\end{array}$} & \multicolumn{2}{|c|}{$\begin{array}{l}\text { Height } \\
\text { (cm) }\end{array}$} & \multicolumn{2}{|c|}{$\begin{array}{c}\text { From Post. End } \\
\text { of Inf. } \\
\text { Turbinate (cm) }\end{array}$} & \multicolumn{2}{|c|}{$\begin{array}{l}\text { Perpendicular } \\
\text { Distance from } \\
\text { Clivus (cm) }\end{array}$} & \multicolumn{2}{|c|}{$\begin{array}{c}\text { From Roof of } \\
\text { Nasopharynx } \\
\text { (cm) }\end{array}$} & \multicolumn{2}{|c|}{$\begin{array}{l}\text { From Ant. } \\
\text { Arch of Atlas } \\
\text { (cm) }\end{array}$} \\
\hline & $\mathbf{R t}$ & Lt & Rt & Lt & Rt & Lt & Rt & Lt & Rt & Lt & Rt & Lt \\
\hline Number & 25 & 25 & 25 & 25 & 25 & 25 & 25 & 25 & 25 & 25 & 25 & 25 \\
\hline $\mathrm{N}$ mean & $\begin{array}{c}0.8 \\
7\end{array}$ & 0.76 & 0.92 & 0.81 & 1.14 & 1.15 & 2.40 & 2.54 & 1.27 & 1.14 & 2.78 & 3.02 \\
\hline S.D. & $\begin{array}{c}0.1 \\
3\end{array}$ & 0.12 & 0.12 & 0.10 & 0.22 & 0.19 & 0.21 & 0.28 & 0.24 & 0.17 & 0.37 & 0.37 \\
\hline T value & \multicolumn{2}{|c|}{3.030} & \multicolumn{2}{|c|}{3.430} & \multicolumn{2}{|c|}{0.25} & \multicolumn{2}{|c|}{2.01} & \multicolumn{2}{|c|}{2.20} & \multicolumn{2}{|c|}{2.31} \\
\hline $\begin{array}{c}\text { Test significant } \\
\text { or not }\end{array}$ & \multicolumn{2}{|c|}{ YES } & \multicolumn{2}{|c|}{ YES } & \multicolumn{2}{|c|}{ NO } & \multicolumn{2}{|c|}{ YES } & \multicolumn{2}{|c|}{ YES } & \multicolumn{2}{|c|}{ YES } \\
\hline $\mathrm{P}$ value & \multicolumn{2}{|c|}{0.0098} & \multicolumn{2}{|c|}{0.0068} & \multicolumn{2}{|c|}{0.8037} & \multicolumn{2}{|c|}{0.0502} & \multicolumn{2}{|c|}{0.0325} & \multicolumn{2}{|c|}{0.0255} \\
\hline
\end{tabular}

Table 2: Showing the Dimensions and Distance of Pharyngeal Opening of Auditory Tube from Posterior End of Inferior Turbinate, Perpendicular Distance from Clivus, Roof of the Nasopharynx, Anterior Arch of Atlas
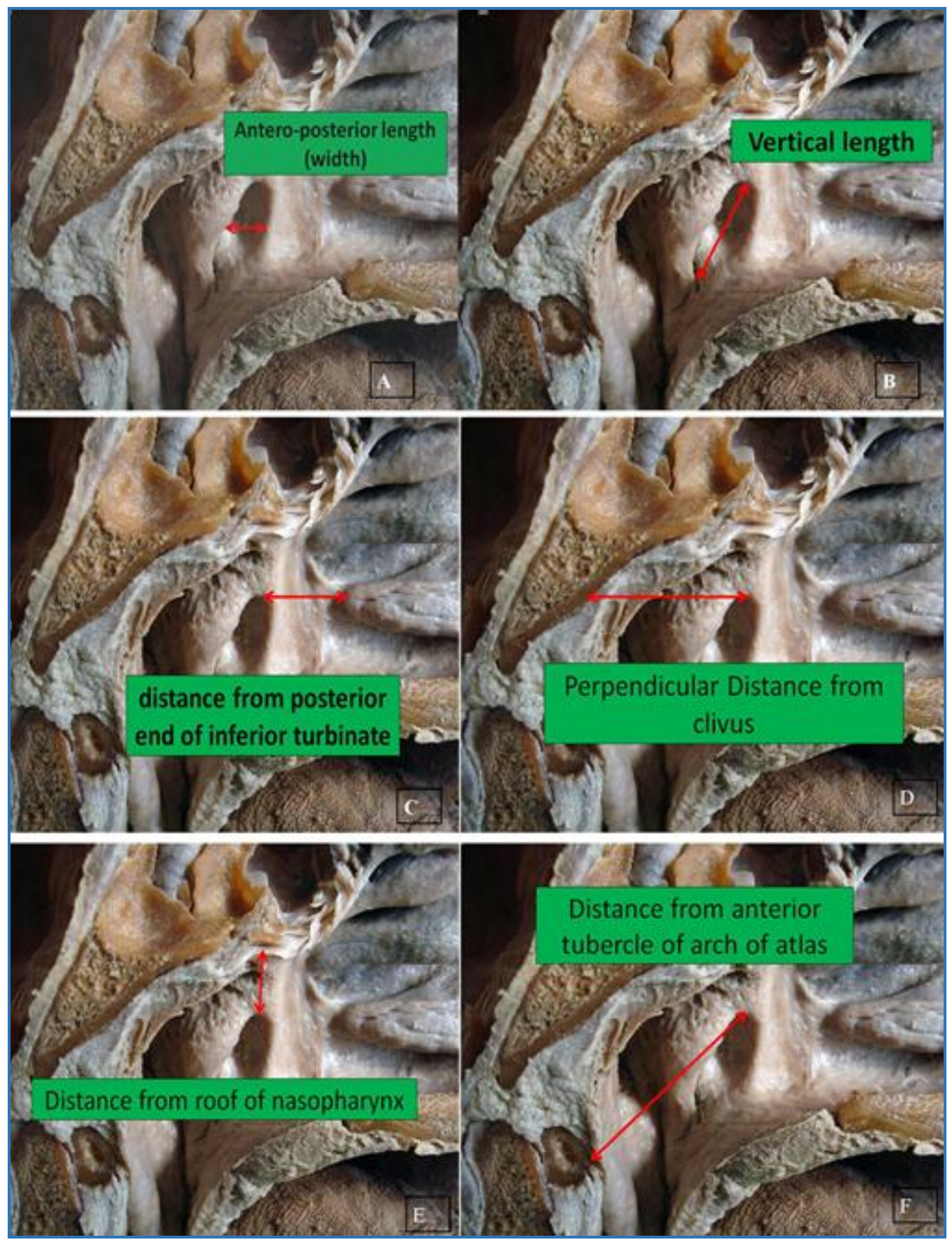

Fig. 1: Showing the Dimensions A-Width, B-Vertical Length and C-Distance of Pharyngeal Opening of Auditory Tube from Posterior End of Inferior Turbinate, D-Perpendicular Distance from Clivus, E-Roof of the Nasopharynx, F-Distance from Anterior Arch of Atlas 


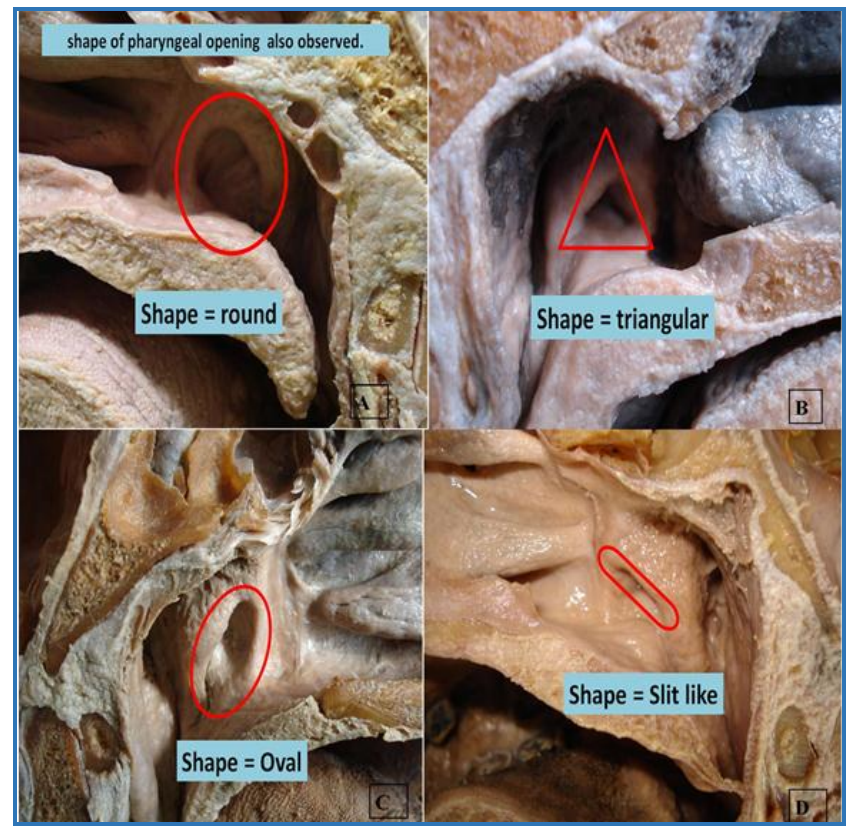

Fig. 2: Showing Shape of the Auditory Tube A-Round, B-Triangular, C-Oval, D-Slit Like
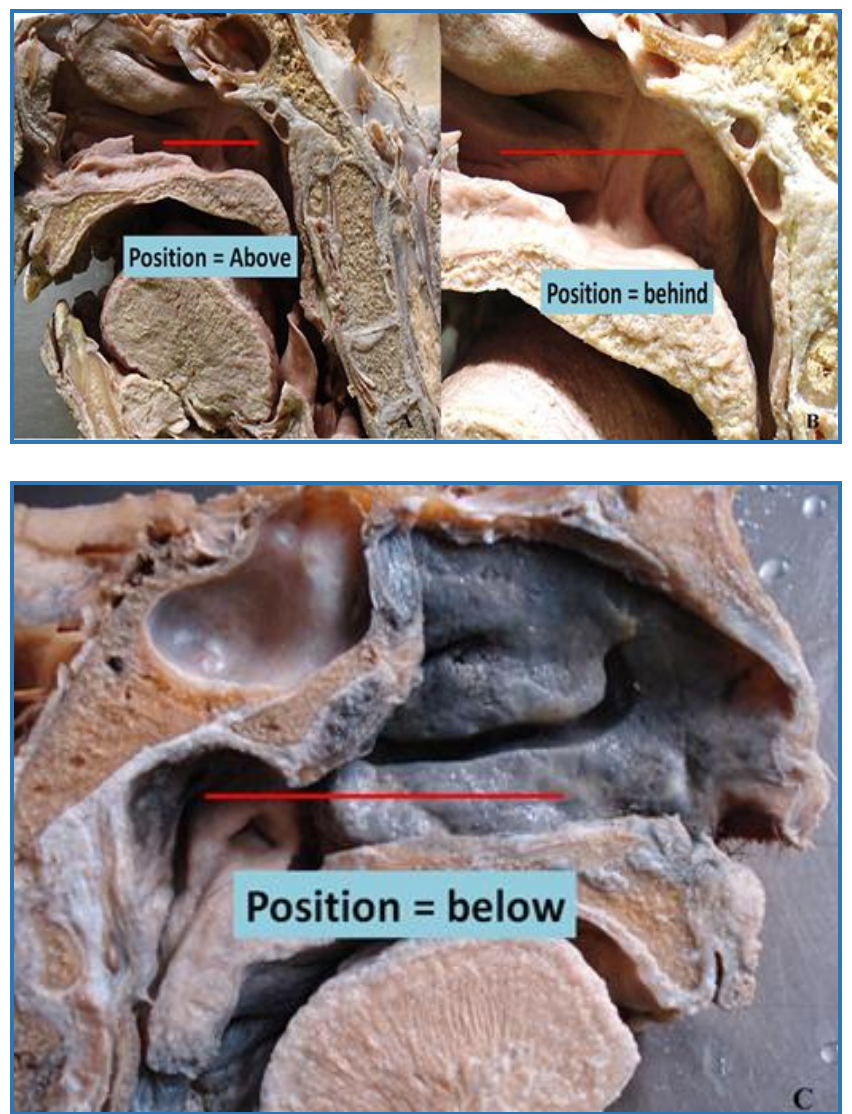

Fig. 3: Showing Position of the Auditory Tube with Respect to Inferior Turbinate

\section{RESULT AND DISCUSSION}

Pharyngeal opening of auditory tube were studied in the 50 specimens. The vertical length and A-P length was taken and shape was observed.
Various shapes of the pharyngeal openings were observed oval shape more common on right side (52\%) and triangular on left (48\%) and the commonest shape was oval. The A-P length on right side was $8.7 \mathrm{~mm}$ on right and $7.6 \mathrm{~mm}$ on left side, which was statistically significant. The height was more on right side than on left side. These measurements were not considered by previous workers. Very few workers like Bluestone. ${ }^{4}$ have worked on pharyngeal opening, but have taken only vertical length. According to Bluestone, it was 8.5 $\mathrm{mm}$ while in present study it was found to be $9.2 \mathrm{~mm}$ on right side and $8.1 \mathrm{~mm}$ on left side. This difference may be due to right dominance and is statistically significant. The mean distance of the opening from posterior end of inferior turbinate on right was $1.14 \mathrm{~cm}$ and on left $1.15 \mathrm{~cm}$. The auditory tube plays an important role in the ventilation of the middle ear. 5 To prevent injury to the carotid artery during AT dissection, the surgeon should identify the junction of the cartilaginous and bony auditory tube as a landmark by following the auditory tube lumen from the nasopharyngeal orifice to the junctional part. 6 The Eustachian tube joins middle ear and nasopharynx and maintains the pressure equilibrium. Pharyngeal opening of auditory tube was studied in the present work. So the study will be helpful for radiologist for diagnosis and ENT surgeons for endoscopic evaluation in patients with chronic otitis media.

\section{SUMMARY AND CONCLUSION}

On available literature search, it reveals that very few research workers worked on morphometry of auditory tube and its clinical importance. In the present work, the exact position of auditory tube can be located by measuring the distances from posterior end of inferior turbinate, perpendicular distance from clivus, roof of the nasopharynx distance from anterior arch of atlas. So the study will be helpful for radiologist for diagnosis and ENT surgeons for endoscopic evaluation in patients with chronic otitis media.

\section{REFERENCES}

1. Standring S. Grays Anatomy. The anatomical basis of clinical practice. $40^{\text {th }}$ edn. Churchill Livingstone, Elsevier 2008.

2. Loh LE, Chee TS, John AB. The anatomy of the fossa of rossenmuller-its possible influence on the detection of occultnasopharyngeal carcinoma. Singapore Medical Journal 1991;32(3):154-5.

3. Shepperd HWH. Scott-Brown's diseases of the ear nose and throat, vol 1: basic sciences. $4^{\text {th }}$ edn. J R Soc Med 1980;73(11):834.

4. Bluestone CD, Paradise JL, Beery QC. Physiology of the eustachian tube in the pathogenesis and management of middle-ear effusions. Laryngoscope 1972;82 (9):165470.

5. Koch KHH. Skeletal growth analysis five years after completion of primary treatment of children with a sailing palate vomer Malformation, Giesen, Germany: University of Giesen Thesis 1994.

6. Koch KHH, Grzonka MA, Koch J. The pathology of the velopharyngeal musculature in cleft palates. Ann Anat 1999;181(1):123-6. 